\title{
CALCULATION OF EIGENVALUES OF DISCRETE SEMIBOUNDED DIFFERENTIAL OPERATORS
}

\author{
S. I. Kadchenko, Nosov Magnitogorsk State Technical University, Magnitogorsk, \\ Russian Federation, sikadchenko@mail.ru, \\ G. A. Zakirova, South Ural State University, Chelyabinsk, Russian Federation, \\ zakirova81@mail.ru.
}

We consider a problem of eigenvalues of an abstract discrete semibounded operator acting in a separable Hilbert space. The existence and uniqueness of the solution, as well as a convergence of the Galerkin method with reference to the problem, are proved. Simple formulas to calculate the eigenvalues are obtained. The formulas based on Galerkin method allow to calculate eigenvalues of discrete semibounded operators with high computational efficiency. In contrast to the classical methods, the formulas sharply reduce the number of calculations. Also, the formulas allow to find eigenvalues of the operator, regardless of whether the eigenvalues with smaller numbers are known or not. The formulas solve the problem on a calculation of all necessary spectrum points of the abstract discrete semibounded operators.

Keywords: eigenvalues, eigenfunctions, perturbation, discrete operator, Galerkin method, existence and uniqueness of the solution.

\section{Introduction}

Consider an abstract discrete semibounded operator $L$, acting in a separable Hilbert space $H$. Let $D_{L} \subset H$ be a domain of $L$. Suppose $L$ is a differential operator. Then its eigenvalues $\mu$ are determined by finding nontrivial solutions of equation

$$
L u=\mu u,
$$

satisfying homogeneous boundary conditions

$$
\left.G u\right|_{\Gamma}=0
$$

where $\Gamma$ is a boundary of domain $D_{L}$.

Consider a spectral problem such that $L$ can be represented as $L=T+P$, where $T$ is a discrete semibounded operator and $P$ is a bounded operator. One of the methods applied to the research of such spectral problems is the Regularized traces method. In 1956 г., in their paper [1] V.A. Sadovnichy and V.E. Podolsky for the first time theoretically justified a calculation of the first eigenvalues of the Sturm-Liouville operator, based on a system of nonlinear equations composed of regularized traces of operator $T$. In future, S.I. Kadchenko obtained linear formulas, which allow to remove existing restrictions on the perturbing operator and essentially expand the range of problems to which the regularized traces method can be applied (see [2]-[10]). S.I. Kadchenko and S.N. Kakushkin developed a non-iterative method in [11]. The method allows to find the values of perturbed discrete operator eigenfunctions beginning with any number, if spectral characteristics of the unperturbed operator and eigenvalues of the perturbed operator are known. The method 
also showed high computational efficiency. The problem was investigated on the basis of the modified Galerkin method in [8].

To calculate eigenvalues of the spectral problem (1), (2), we use the Galerkin method. Consider a sequence $\left\{H_{n}\right\}_{n=1}^{\infty}$ of finite-dimensional spaces $H_{n} \subseteq H$, which is complete in $H$. Suppose an orthonormal basis of the space $H_{n}$ is known and consists of functions $\left\{\varphi_{k}\right\}_{k=1}^{n}$. In addition, the functions $\varphi_{k}$ satisfy the boundary conditions (2). According to the Galerkin method, an approximate solution of the spectral problem (1), (2) can be found in the form:

$$
u_{n}=\sum_{k=1}^{n} a_{k}(n) \varphi_{k} .
$$

We prove the existence and uniqueness of the solution, as well as a convergence of the Galerkin method with reference to the problem. Based on the previously obtained results, we obtain simple formulas to calculate the eigenvalues of the operator $L$ with high computational efficiency.

\section{Support information}

Let us define the terms used in the paper and give some known facts (see. [13], [14]).

We call an operator $L$, acting in a separable Hilbert space $H$, a discrete operator, if there exists a complex number $\lambda_{0}$ such that $R_{\lambda_{0}}=\left(L-\lambda_{0} E\right)^{-1}$ is completely continuous in $H$ (see [13], ch. V, §4).

A spectrum of the discrete operator $L$ consists of isolated points having no limit points, except for infinity.

Definition 1. (see [13], ch. V, §4) If there exists a real number $c$ such that the condition $(L f, f) \geq c(f, f)$ holds for all $f \in D_{L}$, then the operator $L$ is called semibounded below. (If the opposite inequality holds, then the operator is called semibounded above.)

Theorem 1. ([14], ch. I, §6) If $\left\|L_{n}-T\right\| \rightarrow 0$, where $L$ and $L_{n}$ are completely continuous operators, then the characteristic numbers of the equation

$$
u-\lambda L u=0
$$

are obtained by proceeding to limit as $n \rightarrow \infty$ from the characteristic numbers of the equation

$$
u_{n}-\lambda L_{n} u_{n}=0
$$

As is well known (e.g., see [13], ch. V, §4), every semibounded operator can be expressed using some positive operator by means of one of the formulas $L=S+c E, L=S-c E$. Therefore, in future we will consider only positive operators. Since $(L f, f) \geq 0$, then for the eigenfunctions $u_{n}$ the inequalities

$$
\left(L u_{n}, u_{n}\right)=\mu_{n}\left(u_{n}, u_{n}\right) \geq 0
$$

hold, i.e., the eigenvalues of a positive discrete operator are nonnegative and can accumulate only to $+\infty$. 


\section{Main results}

Theorem 2. Let $L$ be a discrete semibounded operator acting in a separable Hilbert space $H$. If a system of coordinate functions $\left\{\varphi_{k}\right\}_{k=1}^{\infty}$ is an orthonormal basis in $H$, then the Galerkin method, which is applied to the problem of finding eigenvalues of the spectral problem (1) and constructed on this system of functions, converges.

Proof. We write equation (1) in the form

$$
\left(L-\lambda_{0} E\right) u=\left(\mu-\lambda_{0}\right) u .
$$

Since the operator $L$ is discrete, then for it there exists a resolvent operator $R_{\lambda_{0}} L=\left(L-\lambda_{0} E\right)^{-1}$, which is completely continuous in $H$. Acting on the left side of both sides of equation (3) by the operator $R_{\lambda_{0}} L$, we obtain

$$
u=\left(\mu-\lambda_{0}\right) M u, \quad M u \equiv R_{\lambda_{0}} L u .
$$

Let us repeat the reasoning of Theorem 1 in ([14], ch.XI,§94) and show that application of the Galerkin method to the problem of finding the eigenvalues of equation (2) is equivalent to finding the eigenvalues of equation

$$
u_{n}=\left(\mu-\lambda_{0}\right) M_{n} u_{n} .
$$

Suppose the system of coordinate functions $\left\{\varphi_{k}\right\}_{k=1}^{\infty}$ is an orthonormal basis of the space $H$. Decompose $M u=R_{\lambda_{0}} L u$ into an orthogonal series

$$
M u=\sum_{k=1}^{\infty}\left(M u, \varphi_{k}\right) \varphi_{k}
$$

and assume

$$
M_{n} u=\sum_{n=1}^{n}\left(M u, \varphi_{k}\right) \varphi_{k} .
$$

The operator $M$ is completely continuous in $H$ and therefore it can be decomposed into a sum $M=M^{\prime}+M^{\prime \prime}$, where $M^{\prime}$ is a degenerate operator, and $\left\|M^{\prime \prime}\right\|<\frac{\varepsilon}{2}, \varepsilon>0$. Then

$$
\left(M-M_{n}\right) u=\sum_{k=n+1}^{\infty}\left(M u, \varphi_{k}\right) \varphi_{k}=\sum_{k=n+1}^{\infty}\left(M^{\prime} u, \varphi_{k}\right) \varphi_{k}+\sum_{k=n+1}^{\infty}\left(M^{\prime \prime} u, \varphi_{k}\right) \varphi_{k} .
$$

First we estimate the second sum in (6):

$$
\begin{aligned}
& \left\|\sum_{k=n+1}^{\infty}\left(M^{\prime \prime} u, \varphi_{k}\right) \varphi_{k}\right\|^{2}=\left(\sum_{k=n+1}^{\infty}\left(M^{\prime \prime} u, \varphi_{k}\right) \varphi_{k}, \sum_{k=n+1}^{\infty}\left(M^{\prime \prime} u, \varphi_{k}\right) \varphi_{k}\right)= \\
& =\sum_{k=n+1}^{\infty}\left(M^{\prime \prime} u, \varphi_{k}\right) \sum_{m=n+1}^{\infty}\left(M^{\prime \prime} u, \varphi_{m}\right)\left(\varphi_{k}, \varphi_{m}\right)=\sum_{k=n+1}^{\infty}\left|\left(M^{\prime \prime} u, \varphi_{k}\right)\right|^{2} .
\end{aligned}
$$


Use the Bessel inequality and obtain

$$
\sum_{k=n+1}^{\infty}\left|\left(M^{\prime \prime} u, \varphi_{k}\right)\right|^{2} \leq\left\|M^{\prime \prime} u\right\|^{2} \leq\left\|M^{\prime \prime}\right\|^{2}\|u\|^{2}<\frac{\varepsilon^{2}}{4}\|u\|^{2} .
$$

Hence,

$$
\left\|\sum_{k=n+1}^{\infty}\left(M^{\prime \prime} u, \varphi_{k}\right) \varphi_{k}\right\|<\frac{\varepsilon}{2}\|u\| .
$$

Estimate the first sum in (6). By definition, the degenerate operator $M^{\prime} u$ has the form ([14], ch.XI, $\S 94)$

$$
M^{\prime} u=\sum_{j=1}^{s}\left(u, \psi_{j}\right) \omega_{j}
$$

where $s$ is a finite number, and $\psi_{j}$ and $\omega_{j}$ are elements of the space $H$. Thus,

$$
\begin{gathered}
\left\|\sum_{k=n+1}^{\infty}\left(M^{\prime} u, \varphi_{k}\right) \varphi_{k}\right\|=\left\|\sum_{k=n+1}^{\infty}\left(\sum_{j=1}^{s}\left(u, \psi_{j}\right) \omega_{j}, \varphi_{k}\right) \varphi_{k}\right\|= \\
=\left\|\sum_{k=n+1}^{\infty} \sum_{j=1}^{s}\left(\left(u, \psi_{j}\right) \omega_{j}, \varphi_{k}\right) \varphi_{k}\right\|=\left\|\sum_{k=n+1}^{\infty} \sum_{j=1}^{s}\left(u, \psi_{j}\right)\left(\omega_{j}, \varphi_{k}\right) \varphi_{k}\right\|= \\
=\left\|\sum_{j=1}^{s}\left(u, \psi_{j}\right) \sum_{k=n+1}^{\infty}\left(\omega_{j}, \varphi_{k}\right) \varphi_{k}\right\| \leq \sum_{j=1}^{s}\left|\left(u, \psi_{j}\right)\right| \cdot\left\|\sum_{k=n+1}^{\infty}\left(\omega_{j}, \varphi_{k}\right) \varphi_{k}\right\| \leq \\
\leq\|u\| \sum_{j=1}^{s}\left\|\psi_{j}\right\| \sqrt{\sum_{k=n+1}^{\infty}\left|\left(\omega_{j}, \varphi_{k}\right)\right|^{2} .}
\end{gathered}
$$

The number series $\sum_{k=n+1}^{\infty}\left|\left(\omega_{j}, \varphi_{k}\right)\right|^{2}$ converges. Then there always exists a number $N_{\varepsilon}$ such that for all $n \geq N_{\varepsilon}$ a coefficient of $\|u\|$ is less than $\frac{\varepsilon}{2}$

$$
\left\|\sum_{k=n+1}^{\infty}\left(M^{\prime} u, \varphi_{k}\right) \varphi_{k}\right\|<\frac{\varepsilon}{2}\|u\|
$$

Then it follows from (6)-(8) that for $n \geq N_{\varepsilon}$ the inequality $\left\|\left(M-M_{n}\right) u\right\|<\varepsilon$ or $\left\|M-M_{n}\right\|<\varepsilon$ holds.

On the basis of Theorem 1, if $\left\|M-M_{n}\right\| \rightarrow 0$ as $n \rightarrow \infty$ and $M, M_{n}$ are completely continuous operators, then the eigenvalues of equation (4) are obtained from the eigenvalues of equation (5) by proceeding to limit as $n \rightarrow \infty$.

N.I. Polsky introduced the so-called (A)-condition, or the Polsky condition, of the projection methods convergence (e.g., see [17]). Also, N.I. Polsky noted that for a positive operator this condition in the Galerkin method automatically holds. Thus, under the conditions of Theorem 3 and on the basis of the results obtained in papers [15]-[17], the eigenvalues of equation (1) can be obtained as the limits of approximate eigenvalues. Hence, we have 
Theorem 3. If $L$ is a discrete semibounded operator acting in a separable Hilbert space $H$, then there exists a unique solution of the problem of finding the eigenvalues and eigenfunctions of the operator L. Approximate values of the eigenvalues can be found by the Galerkin method.

Let $\widetilde{\mu}_{k}(n)$ be $n$-th approximate eigenvalues of $k$-th eigenvalue $\mu_{k}$ of the operator $L$ found by the Galerkin method. Then on the basis of Theorems 1 and 2 we have

$$
\lim _{n \rightarrow \infty} \widetilde{\mu}_{k}(n)=\mu_{k}, k \in N
$$

The following theorem was proved in the paper [12].

Theorem 4. Let $L$ be a discrete semibounded operator acting in a separable Hilbert space $H$. If a system of coordinate functions $\left\{\varphi_{k}\right\}_{k=1}^{\infty}$ is an orthonormal basis in $H$ and satisfies the homogeneous boundary conditions (2), then approximate eigenvalues $\widetilde{\mu}_{k}$ of the operator $L$ are found by the formulas [12]

$$
\widetilde{\mu}_{k}(n)=\left(L \varphi_{k}, \varphi_{k}\right)+\delta_{n}, k=\overline{1, n},
$$

where $\delta_{n}=\sum_{k=1}^{n-1}\left[\widetilde{\mu}_{k}(n-1)-\widetilde{\mu}_{k}(n)\right]$.

Note that for any $k \in N \lim _{n \rightarrow \infty}\left(\widetilde{\mu}_{k}(n-1)-\widetilde{\mu}_{k}(n)\right)=0$, therefore $\lim _{n \rightarrow \infty} \delta_{n}=0$. Then from (9) and (10) we obtain

$$
\mu_{k}=\left(L \varphi_{k}, \varphi_{k}\right), \forall k \in N
$$

Thus, the following theorem is proved.

Theorem 5. Let $L$ be a discrete semibounded operator acting in a separable Hilbert space $H$. If a system of coordinate functions $\left\{\varphi_{k}\right\}_{k=1}^{\infty}$ is an orthonormal basis in $H$ and satisfies the homogeneous boundary conditions of spectral problem (1), (2), then eigenvalues $\mu_{k}$ of the operator $L$ are found by the formulas (11).

The formulas (11) obtained by the Galerkin method allow to calculate eigenvalues of discrete semibounded operators with high computational efficiency. In contrast to the classical methods, the formulas (11) sharply reduce the number of calculations. Also, the formulas allow to find eigenvalues of the operator $L$, regardless of whether the eigenvalues with smaller numbers are known or not. The formulas solve the problem on a calculation of all necessary spectrum points of the abstract discrete semibounded operators.

\section{Computational Experiments}

In order to verify the obtained formulas (11), which allow to calculate eigenvalues of discrete semibounded operators, we consider the spectral problem

$$
\left\{\begin{array}{l}
-u^{\prime \prime}+p_{1}(x) u^{\prime}+p_{2}(x) u=\mu u, a<x<b \\
\cos \alpha u^{\prime}(a)+\sin \alpha u(a)=0, \\
\cos \beta u^{\prime}(b)+\sin \beta u(b)=0, \quad \alpha, \beta \in R .
\end{array}\right.
$$


The functions $p_{1}(x), p_{2}(x)$ are continuous on the interval $[a, b]$. In order to construct a system of coordinate functions $\left\{\varphi_{k}\right\}_{k=1}^{\infty}$ in the Galerkin method, which satisfies the boundary conditions (12), we find eigenvalues and eigenfunctions of the auxiliary spectral problem

$$
\left\{\begin{array}{l}
-\varphi^{\prime \prime}=\lambda \varphi, a<x<b, \\
\cos \alpha \varphi^{\prime}(a)+\sin \alpha \varphi(a)=0, \\
\cos \beta \varphi^{\prime}(b)+\sin \beta \varphi(b)=0, \quad \alpha, \beta \in R .
\end{array}\right.
$$

The eigenvalues $\lambda_{k}$ of the problem (13) are roots of a transcendental equation

$$
\begin{gathered}
{[\sin \alpha \sin (\sqrt{\lambda} a)+\sqrt{\lambda} \cos \alpha \cos (\sqrt{\lambda} a)] \times[\sin \beta \cos (\sqrt{\lambda} b)-\sqrt{\lambda} \cos \beta \sin (\sqrt{\lambda} b)]+} \\
+[\sqrt{\lambda} \cos \alpha \sin (\sqrt{\lambda} a)-\sin \alpha \cos (\sqrt{\lambda} a)] \times[\sin \beta \sin (\sqrt{\lambda} b)+\sqrt{\lambda} \cos \beta \cos (\sqrt{\lambda} b)]=0,
\end{gathered}
$$

and the eigenfunctions have the form:

$$
\begin{aligned}
& \varphi_{k}(x)=C_{k}\left\{\left[\sin \alpha \sin \left(\sqrt{\lambda_{k}} a\right)+\sqrt{\lambda_{k}} \cos \alpha \cos \left(\sqrt{\lambda_{k}} a\right)\right] \cos \left(\sqrt{\lambda_{k}} x\right)+\right. \\
& \left.+\left[\sqrt{\lambda_{k}} \cos \alpha \sin \left(\sqrt{\lambda_{k}} a\right)-\sin \alpha \cos \left(\sqrt{\lambda_{k}} a\right)\right] \sin \left(\sqrt{\lambda_{k}} x\right)\right\}, \quad k=\overline{1, \infty} .
\end{aligned}
$$

The constants $C_{k}$ are found from the normalization condition.

Let $\left\{\widetilde{\mu}_{k}\right\}_{k=1}^{n}$ and $\left\{\widehat{\mu}_{k}\right\}_{k=1}^{n}$ be eigenvalues of the Sturm-Liouville spectral problem found by the formulas (11) and the Galerkin method, respectively. We compare the results of the eigenvalues calculation. An example of calculation of the boundary problem (12) eigenvalues is given in Table for $a=0, b=1, \alpha=P i / 3, \beta=P i / 5$, $p_{1}(x)=-2 \sin (5 x)+3 x, p_{0}(x)=-3 \cos (2 x)+x$. As the number of basic functions used in the Galerkin method increases, the values of approximate eigenvalues $\left\{\widehat{\mu}_{k}\right\}_{k=1}^{n}$ found by the Galerkin method approach to the eigenvalues $\left\{\widetilde{\mu}_{k}\right\}_{k=1}^{n}$ found by the formulas (11).

\section{Table}

\begin{tabular}{|c|c|c|c|}
\hline$k$ & $\widetilde{\mu}_{k}$ & $\widehat{\mu}_{k}$ & $\left|\widetilde{\mu}_{k}-\widehat{\mu}_{k}\right|$ \\
\hline 1 & 10,541004 & 10,628951 & 0,087947 \\
2 & 39,303090 & 41,233238 & 1,930148 \\
3 & 88,515916 & 90,163626 & 1,861448 \\
4 & 157,556701 & 159,191315 & 1,634614 \\
5 & 246,361792 & 247,960088 & 1,598295 \\
6 & 354,915883 & 356,506057 & 1,590174 \\
7 & 483,213785 & 484,793380 & 1,579595 \\
8 & 631,253343 & 632,828726 & 1,575384 \\
9 & 799,033529 & 800,603920 & 1,570392 \\
10 & 985,553804 & 988,121318 & 1,587514 \\
11 & 1193,813863 & 1195,378096 & 1,564233 \\
12 & 1420,813523 & 1422,375281 & 1,561758 \\
13 & 1667,552667 & 1669,111637 & 1,558971 \\
14 & 1934,031219 & 1935,587668 & 1,556449 \\
15 & 2220,249128 & 2221,802734 & 1,553606 \\
16 & 2526,206359 & 2527,757093 & 1,550734 \\
17 & 2851,902885 & $2853,45 O 361$ & 1,547476 \\
18 & 3197,338688 & 3198,882655 & 1,543967 \\
19 & 3562,513753 & 3564,053703 & 1,539950 \\
20 & 3947,428071 & 3948,963524 & 1,535453 \\
21 & 4352,081633 & 4353,611879 & 1,530246 \\
\hline
\end{tabular}




\section{Conclusion}

The theorem on the existence and uniqueness of solution of the problem on finding eigenvalues and eigenfunctions of discrete semibounded operators is proved. The theorem on the convergence of the Galerkin method in application to the problem on finding eigenvalues is proved. Simple formulas to calculate the eigenvalues are obtained. In contrast to the classical methods, the formulas sharply reduce the number of calculations. Also, the formulas allow to find eigenvalues of the operator, regardless of whether the eigenvalues with smaller numbers are known or not. The formulas solve the problem on a calculation of all necessary spectrum points of the abstract discrete semibounded operators.

\section{References}

1. Sadovnichii V.A., Podolskii V.E. On the Calculation of the First Eigenvalues of the Sturm - Liouville Operator. Doklady Akademii nauk, 1996, vol. 346, no. 2. pp. 162-164. (in Russian)

2. Kadchenko S.I., Kinzina I.I. Computation of Eigenvalues of Perturbed Discrete Semibounded Operators. Computational Mathematics and Mathematical Physics, 2006, vol. 46, issue 7, pp. 1200Џ1206. doi: 10.1134/S0965542506070116

3. Kadchenko S.I., Ryazanov L.S. A Numerical Method to Find the Eigenvalues of Discrete Semibounded below Operators. Bulletin of the South Ural State University. Series: Mathematical Modelling, Programming and Computer Software, 2011, no. 17 (234), issue 8, pp. 46-51. (in Russian)

4. Kakushkin S.N., Kadchenko S.I. The Calculation of Values of Eigenfunctions of the Perturbed Self-Adjoint Operators by Regularized Traces Method. Journal of Computational and Engineering Mathematics, 2015, vol. 2, no. 4, pp. 48-60. doi: $10.14529 /$ jcem 150405

5. Kadchenko S.I., Ryazanova L.S. Calculation of Eigenvalues of a Spectral Problem OrrSommerfeld by the Method of Regularized Traces. Software of systems in the industrial and social fields, 2014, no. 2(5), pp. 3-18. (in Russian)

6. Kadchenko S.I., Ryazanova L.S., Kadchenko A.I. Calculation of the Eigenvalues of the Orr-Sommerfeld Spectral Problem by the Method of Regularized Traces. International Conference "Algorithmic Analysis of Unstable Problems". Chelyabinsk, Russia: November 10 - November 14, 2014. Proceedings of Conference. Chelyabinsk, Publishing Centre of SUSU, 2014, pp. 124-126. (in Russian)

7. Sadovnichii V.A., Dubrovskii V.V., Kadchenko S.I., Kravchenko V.F. The Calculation of Eigenvalues of Problem for Hydrodynamic Stability of Current of Viscous Fluid between Two Rotational Cylinders with Little Numbers of Reinolds. Doklady Akademii nauk, 1998, vol. 363, no. 6. pp. 748-750. (in Russian)

8. Kadchenko S.I., Zakirova G.A. Computation of Eigenvalues of Discrete Lower Semibounded Operators. Applied Mathematical Sciences, 2016, vol. 10, no. 7. pp. 323329. doi: 10.12988/ams.2016.510625 
9. Kadchenko S.I., Zakirova G.A. Numerical Method for Inverse Spectral Problems. Bulletin of the South Ural State University. Series: Mathematical Modelling, Programming and Computer Software, 2015, vol. 8, no. 3. pp. 116-126. doi: $10.14529 / \mathrm{mmp} 150307$

10. Kadchenko S.I., Kinzina I.I. Linear Equations for the Approximate Calculation of the Perturbed Self-Adjoint Operator Eigenvalues. Electromagnetic Waves and Electronic Systems, 2005, vol. 10, no. 6, pp. 4-12. (in Russian)

11. Kadchenko S.I., Kakushkin S.N. Numerical Methods to Find the Eigenvalues and Eigenfunctions of Self-Adjoint Operators. Bulletin of the South Ural State University. Series: Mathematical Modelling, Programming and Computer Software, 2012, no. 27(286), issue 13, pp. 45-57. (in Russian)

12. Kadchenko S.I. A numerical Method to Solve the Inverse Spectral Problems Generated by Perturbed Self-Adjoint Operators. Vestnik SamGU. Estestvenno-Nauchnaya Ser., 2013, no. 9/1(100), pp. 5-11. (in Russian)

13. Sadovnichii V.A. Theory of Operators. Moscow, Vysshaya Shkola Publ., 1999. (in Russian)

14. Mikhlin S.G. Variational Methods in Mathematical Physics. Translated by Boddington T. Oxford, Pergamon Press, 1964. doi: 10.1017/S0013091500011834

15. Polskii N.I. Some Generalizations of the Galerkin Method. Doklady Akademii nauk SSSR, 1952, vol. 46, no. 1, pp. 469-472. (in Russian)

16. Polskii N.I. On the Convergence of Certain Approximate Methods of Ananlysis. Ukr. Mat. Journal, 1955, vol. 7, no. 1, p. 56-70. (in Russian)

17. Polskii N.I. About a General Scheme of Application of Approximate Methods, Doklady Akademii nauk SSSR, 1956, vol. 111, no. 6, pp. 1181-1183. (in Russian)

Sergey I. Kadchenko, Doctor of Physico-Mathematical Sciences, Professor, Department of Applied Mathematics and Informatics, Nosov Magnitogorsk State Technical University (Magnitogorsk, Russian Federation), sikadchenko@mail.ru

Galiya A. Zakirova, Candidate of Physico-Mathematical Sciences, Docent, Department of Equations of Mathematical Physics, South Ural State University (Chelyabinsk, Russian Federation), zakirova81@mail.ru

Received March 10, 2017 


\title{
ВЫЧИСЛЕНИЕ СОБСТВЕННЫХ ЗНАЧЕНИЙ ДИСКРЕТНЫХ ПОЛУОГРАНИЧЕННЫХ ДИФФЕРЕНЦИАЛЬНЫХ ОПЕРАТОРОВ
}

\author{
С. И. Кадченко, Г. А. Закирова
}

\begin{abstract}
В работе рассматривается задача на собственные значения для абстрактного дискретного полуограниченного оператора, действующего в сепарабельном гильбертовом пространстве. Доказываются теоремы о существовании и единственности решения данной спектральной задачи, а так же доказана сходимость метода Галеркина применительно к этой задаче. На основе метода Галеркина получены формулы для вычисления собственных значений абстрактного дискретного полуограниченного оператора. Данные формулы позволяют проводить расчет собственных значений дискретных полуограниченных операторов с высокой вычислительной эффективностью. В отличие от классических методов, данные формулы резко сокращают количество вычислений. Кроме того, собственные значения оператора можно вычислять, независимо от того, известны или нет все предыдущие собственные значения. В работе представлены результаты вычислительных экспериментов.

Ключевые слова: собственные числа, собственные функции, возмущение, дискретный оператор, метод Галеркина, существование и единственность решения.
\end{abstract}

\section{Литература}

1. Садовничий В.А. О вычислении первых собственных значений оператора Штурма - Лиувилля / В.А. Садовничий, В.Е. Подольский // Доклады Академии наук. - 1996. - Т. 346, № 2. - С. 162-164.

2. Кадченко С.И. Вычисление собственных значений возмущенных дискретных полуограниченных операторов / С.И. Кадченко, И.И. Кинзина // Журн. вычисл. математики и мат. физики. - 2006. - Т. 46, № 7. - С. 1265-1272.

3. Кадченко С.И. Численный метод нахождения собственных значений дискретных полуограниченных снизу операторов / С.И. Кадченко, Л.С. Рязанова // Вестн. Юж.-Урал. гос. ун-та. Серия «Математическое моделирование и программирование». - 2011. - № 17(234), вып. 8. - С. 46-51.

4. Какушкин С.Н. Вычисление значений собственный функций возмущенных самосопряженных операторов методом регуляризованных следов / С.Н. Какушкин, С.И. Кадченко // Journal of Computational and Engineering Mathematics. - 2015. T. 2, № 4. - C. 48-60.

5. Кадченко С.И. Вычисление собственных чисел спектральной задачи ОрраЗоммерфельда методом регуляризованных следов / С.И. Кадченко, Л.С. Рязанова // Математическое и программное обеспечение систем в промышленной и социальной сферах. - 2014. - № 2(5). - С. 3-18.

6. Кадченко С.И. Вычисление собственных значений спектральной задачи ОрраЗоммерфельда методом регуляризованных следов / С.И. Кадченко, Л.С. Рязанова, А.И. Кадченко // Международная конференция «Алгоритмический анализ неустойчивых задач». г. Челябинск, 10 - 14 ноября 2014 года. Тезисы докладов. Челябинск: Издательский центр ЮУрГУ, 2014. - С. 124-126. 
7. Садовничий В.А. Вычисление собственных чисел задачи гидродинамической теории устойчивости течения вязкой жидкости между двумя вращающимися цилиндрами при небольших числах Рейнольса / В.А. Садовничий, В.В. Дубровский, С.И. Кадченко, В.Ф. Кравченко // Доклады Академии наук. - 1998. - Т. 363, № 6. - С. $748-750$.

8. Kadchenko S.I. Computation of eigenvalues of discrete lower semibounded operators / S.I. Kadchenko, G.A. Zakirova // Applied Mathematical Sciences. - 2016. - V. 10, № 7. - P. 323-329.

9. Кадченко С.И. Численный метод решения обратных спектральных задач / С.И. Кадченко, Г.А. Закирова // Вестн. Юж.-Урал. гос. ун-та. Серия «Математическое моделирование и программирование». - 2015. - Т. 8, № 3. - С. 116-126.

10. Кадченко С.И. Линейные уравнения для приближенного вычисления собственных чисел возмущенных самосопряженных операторов / С.И. Кадченко, И.И. Кинзина // Электромагнитные волны и электронные системы. - 2005. T. 10, № $6 .-$ C. 4-12.

11. Кадченко С.И. Численные методы нахождения собственных чисел и собственных функций возмущенных самосопряженных операторов / С.И. Кадченко, С.Н. Какушкин // Вестн. Юж.-Урал. гос. ун-та. Серия «Математическое моделирование и программирование». - 2012. - № 27(286), вып. 13. - С. 45-57.

12. Кадченко С.И. Численный метод решения обратных спектральных задач, порожденных возмущенными самосопряженными операторами / С.И. Кадченко // Вестник Самарского государственного университета. Естественнонаучная серия. - 2013. - № 9/1(100). - С. 5-11.

13. Садовничий В.А. Теория операторов / В.А. Садовничий. - М.: Высшая школа, 1999.

14. Михлин С.Г. Вариационные методы в математической физике / С.Г. Михлин. М.: Наука, 1970.

15. Польский Н.И. Некоторые обобщения метода Б.Г. Галеркина / Н.И. Польский // ДАН СССР. - 1952. - Т. 46, № 1. - С. 469-472.

16. Польский Н.И. О сходимости некоторых приближенных методов анализа Н.И. Польский // Укр. матем. ж. - 1955. - Т. 7, № 1. - С. 56-70.

17. Польский Н.И. Об одной общей схеме применения приближенных методов Н.И. Польский // ДАН СССР. - 1956. - Т. 111, № 6. - С. 1181-1183.

Кадченко Сергей Иванович, доктор физико-математических наук, профессор, кафедра прикладной математики и информатики, Магнитогорский государственный технический университет им. Г.И. Носова (г. Магнитогорск, Российская Феdepauuя), sikadchenko@mail.ru

Закирова Галия Амрулловна, кандидат физико-математических наук, дочент, кафедра уравнений математической физики, Южно-Уральский государственный университет (г. Челябинск, Российская Федерачия), zakirova81@таil.ru

Поступила в редакцию 10 марта 2017 г. 